\title{
Comparison of toxin and spore production in clinically relevant strains of Clostridium difficile
}

\author{
Prerna Vohra and lan R. Poxton \\ Centre for Infectious Diseases, University of Edinburgh College of Medicine and \\ Veterinary Medicine, The Chancellor's Building, 49 Little France Crescent, Edinburgh \\ EH16 4SB, UK
}

Correspondence

lan R. Poxton

i.r.poxton@ed.ac.uk

Received 18 October 2010

Revised 11 February 2011

Accepted 16 February 2011

\begin{abstract}
Clostridium difficile is a major cause of nosocomial diarrhoea. The toxins that it produces (TcdA and $\mathrm{TcdB}$ ) are responsible for the characteristic pathology of $C$. difficile infection ( $\mathrm{CDI}$ ), while its spores persist in the environment, causing its widespread transmission. Many different strains of C. difficile exist worldwide and the epidemiology of the strains is ever-changing: in Scotland, PCR ribotype 012 was once prevalent, but currently ribotypes 106, 001 and 027 are endemic. This study aimed to identify the differences among these ribotypes with respect to their growth, and toxin and spore production in vitro. It was observed that the hypervirulent ribotype 027 produces significantly more toxin than the other ribotypes in the exponential and stationary phases of growth. Further, the endemic strains produce significantly more toxins and spores than ribotype 012 . Of note was the observation that $t c d C$ expression did not decrease into the stationary phase of growth, implying that it may have a modulatory rather than repressive effect on toxin production. Further, the increased expression of $t c d E$ in ribotype 027 suggests its importance in the release of the toxins. It can thus be concluded that several genotypic and phenotypic traits might synergistically contribute to the hypervirulence of ribotype 027 . These observations might suggest a changing trend towards increased virulence in the strains currently responsible for CDI.
\end{abstract}

\section{INTRODUCTION}

Clostridium difficile is a Gram-positive, anaerobic, sporeforming bacillus that was first identified as the cause of antibiotic-associated pseudomembranous colitis in 1978 (Bartlett et al., 1978; George et al., 1978; Larson et al., 1978). Today, it is the most common cause of nosocomial diarrhoea. Once mainly associated with the use of antibiotics and being elderly, it is now also found in young, previously healthy adults with no history of antibiotic usage (McFarland et al., 2007). C. difficile is acquired from the environment in the form of spores and transmitted by the faecal-oral route. The organism is able to colonize the gut when the normal protective flora is disrupted by the use of broad-spectrum antibiotics. Once the infection is established, the bacterium produces two large Rho glucosylating exotoxins, toxin A (TcdA), an enterotoxin, and toxin B (TcdB), a cytotoxin, which result in the characteristic pathology of Clostridium difficile infection (CDI). Though asymptomatic carriage of $C$. difficile is common (Riggs et al., 2007), the presentation of CDI can vary from mild self-limiting diarrhoea to severe diarrhoea, which can progress to pseudomembrane formation, toxic megacolon, perforation, shock and even

Abbreviations: $\mathrm{CDI}$, Clostridium difficile infection; PaLoc, pathogenicity locus. death. During carriage or an infection, patients have the potential to release large amounts of spores into the environment (Jump et al., 2007). In this way, the toxins and spores of $C$. difficile ensure a continual presence and spread in the human population.

TcdA and TcdB are encoded on the $19.6 \mathrm{~kb}$ pathogenicity locus (PaLoc), along with the positive regulator TcdR, the negative regulator TcdC and a putative holin, TcdE. Study of the five genes of the PaLoc has shown an increased transcription of $t c d A, t c d B, t c d R$ and $t c d E$ and a decreased transcription of $t c d C$ during the progression of $C$. difficile from the exponential to the stationary phase of growth (Hundsberger et al., 1997).

Since the early 2000s, ribotype 027 (BI/NAP1) has emerged as the cause of several outbreaks and disease of increased severity, morbidity and mortality (Loo et al., 2005; Pépin et al., 2005). It has been dubbed the hypervirulent strain, following the observation of excessive toxin production by this ribotype: up to 16 times more toxin A and 23 times more toxin B (Warny et al., 2005). An explanation of this increased toxin production has been found in the deletions observed in the $t c d C$ gene of most, but not all, ribotype 027 strains (MacCannell et al., 2006; Spigaglia \& Mastrantonio, 2002). The $\Delta 117$ frameshift mutation results in a truncated protein lacking in 
function. Strains with both $\Delta 117$ and an 18 bp deletion have also been found to produce more toxin in the exponential phase of growth and to cause more severe disease (Curry et al., 2007). However, it has also been shown that this ribotype does not produce more toxin than others, although the duration of the toxin production is increased (Freeman et al., 2007). Interestingly, it has been observed that 027 strains not only produce more toxins but also have increased sporulation rates, giving them an added advantage in dissemination (Akerlund et al., 2008).

The changing epidemiology of C. difficile in Scotland has been studied extensively and has revealed changes in the ribotypes implicated in CDI over the years (Taori et al., 2009). Ribotype 012, to which the reference and the first sequenced strain 630 belongs, represented $5 \%$ of the C. difficile isolates collected between 1979 and 2004, but is no longer reported in the infected population. The incidence of ribotype 001 has increased over the years from 1.5 to $75.8 \%$ (Mutlu et al., 2007). Ribotype 106, not identified in Scottish isolates till 2004, represented $8.1 \%$ of the isolates collected in 2005. In 2006, the prevalence of ribotype 001 started declining and that of ribotype 106 increased steadily. The same year saw the first case of ribotype 027 infection in Scotland, and its incidence has since been on the rise. The most common causes of CDI in Scotland today are ribotypes 106, 001 and 027 (Health Protection Scotland, 2008, 2010).

All the ribotypes mentioned above are multidrug-resistant and have been isolated from CDI patients. Though only ribotype 027 is considered to be hypervirulent, strains 106 and 001 have also been shown to cause severe disease (Arvand et al., 2009; Sundram et al., 2009). Strain 630 was isolated from a patient with pseudomembranous colitis during a diarrhoeal outbreak in a Zurich hospital (Wüst et al., 1982). These observations led to the hypothesis that not only excessive toxin production but also enhanced growth and increased sporulation might explain the severity of disease caused by these strains, as well as their ability to spread in the environment. To test this, the growth of these strains over a $24 \mathrm{~h}$ period was studied, along with toxin production and sporulation. For a more detailed understanding, the transcription of the genes of the PaLoc and the sporulation initiator spo0A were investigated over the same time period. Strain VPI 10463 was used as the reference strain, as it is known to be a high toxin and low spore producer (Akerlund et al., 2006).

\section{METHODS}

Bacterial strains. Three ribotypes of $C$. difficile were used in this study: 027 (a clinical isolate obtained from E. J. Kuijper, Leiden University Medical Center), 001 and 106 (isolates from toxinpositive faecal samples from CDI cases in south-east Scotland; Mutlu et al., 2007). Strain 630 (ribotype 012, obtained from P.
Mullany, UCL Eastman Dental Institute, London, UK) was used as a reference strain, representing a historic isolate. VPI 10463 (obtained from Unipath, Bedford, UK), a known high toxin producer, was the other reference strain. The strains were purified and maintained as spore suspensions in Robertson's cooked meat medium.

Growth measurement. A starter culture was prepared by inoculating $0.5 \mathrm{ml}$ of the spore suspension into $3 \mathrm{ml}$ pre-reduced anaerobic incubation medium (AIM) (Brown et al., 1996). This was incubated anaerobically $\left(80 \% \mathrm{~N}_{2}, 10 \% \mathrm{H}_{2}, 10 \% \mathrm{CO}_{2}\right)$ for $16 \mathrm{~h}$ at $37{ }^{\circ} \mathrm{C}$ in a Mark III workstation (Don Whitley Scientific) till $\mathrm{OD}_{600} 1.0$ $( \pm 0.05)$ was achieved. The starter culture $(3 \mathrm{ml})$ was inoculated into $300 \mathrm{ml}$ pre-reduced AIM. Growth was determined by measuring $\mathrm{OD}_{600}$ at 4, 8, 12, 16, 20 and $24 \mathrm{~h}$. Cultures were checked for purity by Gram-staining and aerobic and anaerobic subculture on blood agar. All growth curves and related studies were performed in triplicate.

Total toxin production. Total toxin $(\mathrm{A}+\mathrm{B})$ production was measured using the C. difficile TOX A/B II kit (TechLab) according to the manufacturer's instructions. Culture supernatants were collected every $4 \mathrm{~h}$ by centrifugation at $13000 \mathrm{~g}$ for $1 \mathrm{~min}$ and stored at $-80{ }^{\circ} \mathrm{C}$. The supernatants were diluted $1: 5$ in the supplied diluent and run in duplicate. Total toxin levels were determined by measuring $A_{450} / \mathrm{OD}_{600}$.

ELISA for toxin A. A sandwich ELISA was developed for the quantification of toxin A. ELISA plates were coated with $50 \mu \mathrm{l}$ of $1.5 \mu \mathrm{g} \mathrm{ml}{ }^{-1}$ rabbit polyclonal antibody to $C$. difficile toxin A (Meridian Life Science) in $0.1 \mathrm{M}$ carbonate/bicarbonate buffer ( $\mathrm{pH}$ 9.6). The plates were incubated at $4{ }^{\circ} \mathrm{C}$ overnight. They were then washed with PBS ( $\mathrm{pH} 7.4$ ) containing $0.05 \%$ Tween 20 and blocked with $100 \mu \mathrm{l}$ PBS containing $3 \%$ gelatin. Culture supernatants $(50 \mu \mathrm{l})$ diluted in PBS with $1 \%$ gelatin were then added to the plate in duplicate and incubated. To generate standard curves, twofold dilutions of toxin A (Calbiochem, Merck) from 250 to $0.25 \mathrm{ng} \mathrm{ml}^{-1}$ were added to each plate. The plates were washed as above and $50 \mu \mathrm{l}$ of $0.5 \mu \mathrm{g} \mathrm{ml}^{-1}$ mouse monoclonal antibody to toxin A (Novus Biologicals) was added to the plate and incubated. After washing, $50 \mu 11: 1000$ anti-mouse IgG (whole molecule)-peroxidase antibody produced in rabbits (Sigma) was added to the plates. All the above incubations were performed for $1 \mathrm{~h}$ at $37^{\circ} \mathrm{C}$. Finally, the plates were washed and $100 \mu \mathrm{l}$ substrate, 3,3',5,5' -tetramethylbenzidine (TMB), was added for $5 \mathrm{~min}$ at room temperature. The reaction was stopped with $100 \mu \mathrm{l} 0.2 \mathrm{M} \mathrm{H}_{2} \mathrm{SO}_{4}$ and $A_{450}$ was measured.

Quantitative cytotoxicity assay for toxin B. It proved impossible to develop an ELISA for toxin B with commercially available reagents, and thus a modified cytotoxicity assay was performed for its quantification. Vero cells were cultured in Dulbecco's Modified Eagle's medium (DMEM) with $10 \%$ fetal bovine serum, $1 \%$ nonessential amino acids, 100 units penicillin $\mathrm{ml}^{-1}$ and $100 \mu \mathrm{g}$ streptomycin $\mathrm{ml}^{-1}$ at $37^{\circ} \mathrm{C}$ in $5 \% \mathrm{CO}_{2}$. The monolayers were trypsinized at $37^{\circ} \mathrm{C}$ for $5 \mathrm{~min}$, washed with medium and resuspended at $5 \times 10^{5}$ cells $\mathrm{ml}^{-1}$. The cells were added to a 96-well tissue culture plate in $50 \mu \mathrm{l}$ volumes and incubated overnight. The medium was replaced with $50 \mu \mathrm{l}$ of suitable dilutions of culture supernatant prepared in medium, in duplicate. To generate standard curves, twofold dilutions of toxin B (Calbiochem, Merck) from 250 to $0.25 \mathrm{ng} \mathrm{ml}^{-1}$ were added to each plate. The plates were incubated for $48 \mathrm{~h}$, washed with pre-warmed PBS and then $20 \mu \mathrm{l} \mathrm{of} 5 \mu \mathrm{g} \mathrm{ml}$ thiazolyl blue tetrazolium bromide (Sigma) was added to the wells, followed by incubation at $37{ }^{\circ} \mathrm{C}$ for $4 \mathrm{~h}$. Any formazan produced by the cells was dissolved in $100 \mu \mathrm{l}$ DMSO (Sigma) and $A_{570}$ was measured. 
Real-time RT-PCR. Transcriptional analysis of the PaLoc genes and spo0A was performed. Culture was collected every $4 \mathrm{~h}$ corresponding to approximately $5 \times 10^{8}$ cells $(50 \mathrm{ml}$ at $4 \mathrm{~h}$ to $5 \mathrm{ml}$ at $24 \mathrm{~h}$ ) by centrifuging at $4000 \mathrm{~g}$ for $10 \mathrm{~min}$. The pellets obtained were immediately treated with $500 \mu \mathrm{l}$ RNAwiz (Ambion) or TRIzol (Invitrogen), vortexed vigorously in a Mini-BeadBeater (Biospec Products) and stored at $-80{ }^{\circ} \mathrm{C}$ for a maximum of 7 days before use. RNA was extracted according to the manufacturer's instructions and treated with DNase I (Ambion) at $37{ }^{\circ} \mathrm{C}$ for $1 \mathrm{~h}$, followed by deactivation of the DNase with DNase Inactivation Reagent (Ambion) for $2 \mathrm{~min}$ at room temperature. The quantity and quality of the RNA were assessed using a NanoDrop spectrophotometer, and aliquots were stored at $-80{ }^{\circ} \mathrm{C}$. The SuperScript VILO cDNA Synthesis kit (Invitrogen) was used to convert $2 \mu \mathrm{g}$ RNA into cDNA according to the manufacturer's instructions. The cDNA was aliquoted and stored at $-20^{\circ} \mathrm{C}$. Primers for $t c d A, t c d B, t c d C$, $t c d R, t c d E, s p o 0 A$ and $r r n$ (16S rRNA gene) were designed using Primer3 software (Rozen \& Skaletsky, 2000) based on the genome of strain 630 (Table 1). These were first tested by conventional PCR with genomic DNA to confirm specificity and product size. The realtime RT-PCRs were performed in duplicate in $20 \mu \mathrm{l}$ volumes using $50 \mathrm{ng}$ cDNA, primers at $200 \mathrm{nM}$ for $t c d A-R, 500 \mathrm{nM}$ for $t c d E$ and $100 \mathrm{nM}$ for spoOA and $\mathrm{rrn}$, and $10 \mu \mathrm{l}$ SYBR Green JumpStart Taq ReadyMix (Sigma) in an Mx3000P quantitative PCR system (Stratagene). Standard curves were generated using fourfold dilutions of cDNA pools on each plate for each gene to determine the efficiency of the reactions. RNA and diethylpyrocarbonate (DEPC) water controls were also maintained. The thermal profile used was: initial denaturation at $95{ }^{\circ} \mathrm{C}$ for $3 \mathrm{~min}, 40$ cycles of denaturation at $95{ }^{\circ} \mathrm{C}$ for $20 \mathrm{~s}$, annealing at $56{ }^{\circ} \mathrm{C}$ for $20 \mathrm{~s}$, and extension at $72{ }^{\circ} \mathrm{C}$ for $20 \mathrm{~s}$. This was followed by a dissociation curve to check the product specificity. The expression of the test genes was normalized to that of $r r n$ and calculated by the Pfaffl method (Pfaffl, 2001) using the amplification efficiencies determined in each run. The $4 \mathrm{~h}$ value was used as the calibrator for expression at the successive time points.

Spore production. Spore production was assessed using $10 \mathrm{ml}$ of the culture every $4 \mathrm{~h}$ from the same culture as above. Pellets were obtained by centrifugation at $4000 \mathrm{~g}$ for $10 \mathrm{~min}$, washed twice in distilled water and treated with $50 \%$ ethanol for $1 \mathrm{~h}$. After washing twice, the pellets were suspended in $1 \mathrm{ml}$ distilled water and 10-fold

Table 1. Primer pairs used to amplify the genes studied by real-time RT-PCR

\begin{tabular}{|c|c|}
\hline Gene & Primer sequence \\
\hline \multirow[t]{2}{*}{$\operatorname{tcd} A$} & 5'-GCTATTGCTGCAGTCGGATT-3' \\
\hline & 3'-TACCATTAACAGTCTGCCAACC-5' \\
\hline \multirow[t]{2}{*}{$\operatorname{tcdB}$} & 5'-TGGTGAAGATGGTGTCATGC-3' \\
\hline & 3'-ТTCТСССТСААААТТСТСАТСС-5' \\
\hline \multirow[t]{2}{*}{$\operatorname{tcd} C$} & 5'-TTTAAGAGCACAAAGGGTATTGC-3' \\
\hline & 3'-TGACCTCCTCATGGTCTTCAG-5' \\
\hline \multirow[t]{2}{*}{$t c d R$} & 5'-AACTCAGTAGATGATTTGCAAGAA-3' \\
\hline & 3'-TTAAATCTGTTTCTCCСТCTTCA-5' \\
\hline \multirow[t]{2}{*}{$\operatorname{tcd} \mathrm{t}$} & 5'-AAATATGTGCTTATGTGGATTACCAG-3' \\
\hline & 3'-TTCATCCTTAGCATTCATTTCATC-5' \\
\hline \multirow[t]{2}{*}{ spooA } & 5'-TGTTGAGCTTTTAGGTGCAG-3' \\
\hline & 3'-TGCATGTCTTATTGCTCTTTCAA-5' \\
\hline \multirow[t]{2}{*}{$r r n$} & 5'-AGTGAAAGGCTACGGCTCAA-3' \\
\hline & 3'-CTACGCATTTCACCGCTACA-5' \\
\hline
\end{tabular}

serial dilutions were plated onto blood agar. After anaerobic incubation for $48 \mathrm{~h}$, the colonies were counted and the number of spores per millilitre of culture was determined.

Statistical analysis. Statistical analyses were performed using GraphPad Prism 4.0 software. Strain comparison at individual time points was performed by one-way ANOVA. To assess the overall trends of growth and the corresponding phenotypic traits over the time-course, area under curve (AUC) analysis was performed for each strain, and strains were then compared by one-way ANOVA.

\section{RESULTS AND DISCUSSION}

The hypervirulence of ribotype 027 has been of increasing interest since the emergence of this strain and its apparent ability to cause severe disease and be responsible for many outbreaks (Kuijper et al., 2007; Pépin et al., 2004; Smith, 2005). The hypervirulence has been directly associated with the excessive toxin production observed in this ribotype. Here we show that ribotype 027 produces much greater amounts of toxin than other strains in this study. Also, ribotypes 106 and 001 produce more toxins than strain 630 , and ribotype 106 produces markedly more spores than the other strains.

\section{All the C. difficile strains show similar patterns of growth}

The growth curves obtained for all the $C$. difficile strains were similar (Fig. 1). Ribotypes 001 and 106 showed slightly but significantly increased growth at $4 \mathrm{~h}$ when compared with strains 630 and VPI 10463 $(P<0.001)$, but not when compared with ribotype 027 . Throughout the $24 \mathrm{~h}$, the growth of all the strains was

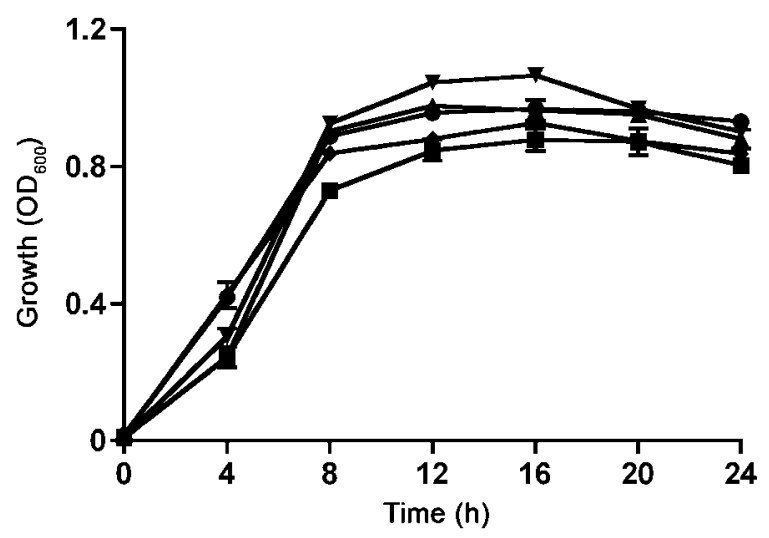

Fig. 1. Growth curves of five C. difficile strains. The growth of strain $630(\boldsymbol{\nabla})$, VPI $10463(\boldsymbol{\Delta})$, ribotype $027(\boldsymbol{\nabla})$, ribotype 001 $(\diamond)$ and ribotype $106(\bullet)$ was measured by $\mathrm{OD}_{600}$ over $24 \mathrm{~h}$. The patterns of growth were similar for all the strains. Error bars, SEM of 12 growth curves (performed in triplicate on four different occasions). 

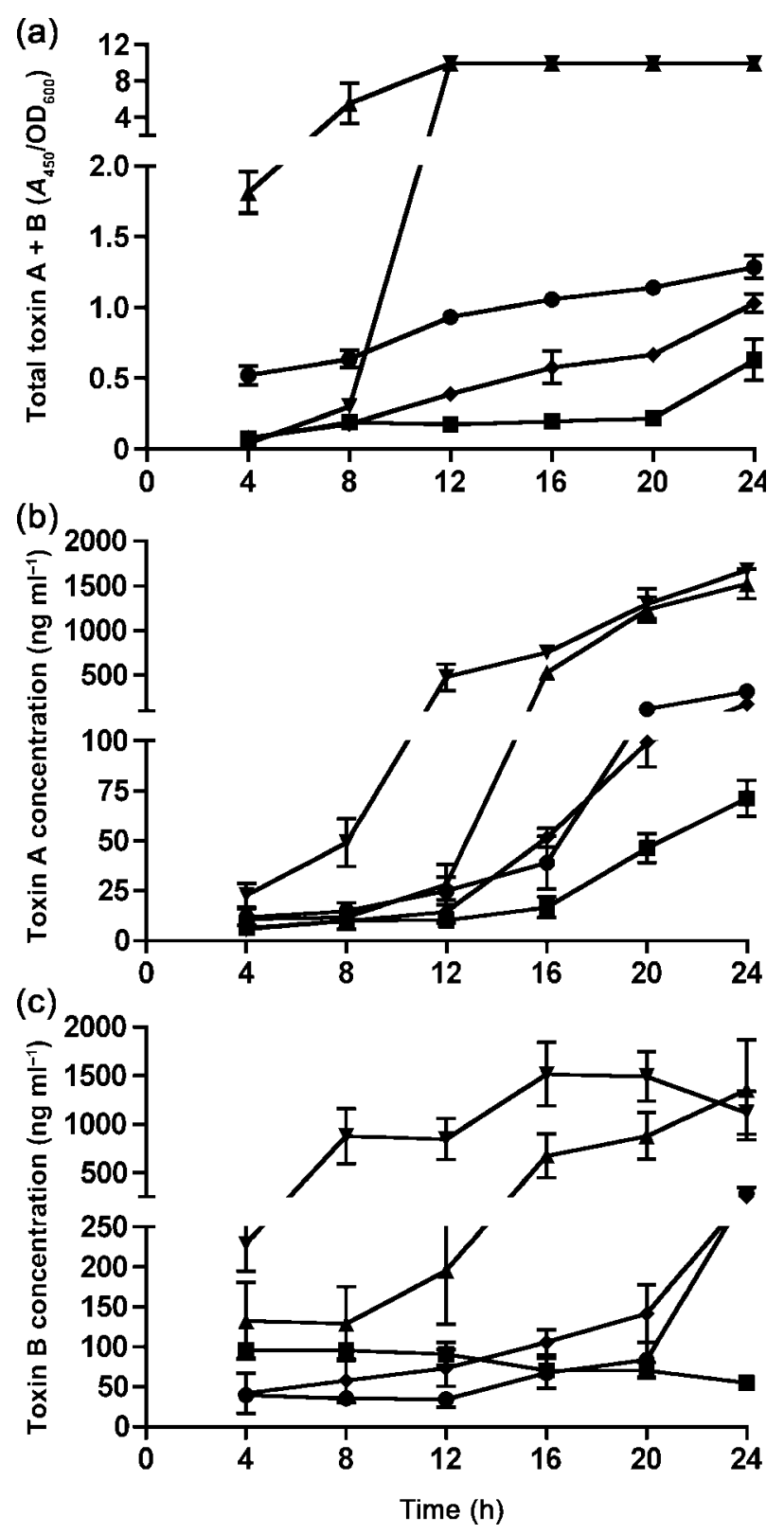

Fig. 2. Toxin production in five C. difficile strains. Toxin production in strain $630(\boldsymbol{\nabla})$, VPI $10463(\boldsymbol{\Delta})$, ribotype $027(\boldsymbol{\nabla})$, ribotype $001(\boldsymbol{)})$ and ribotype $106(\boldsymbol{O})$ was measured over the $24 \mathrm{~h}$ period studied. (a) Total toxin production $(A+B)$ measured using a combined kit showed significantly higher toxin production in ribotype 027 and VPI 10463. Error bars, SEM of three experiments. (b) Toxin A was quantified by a newly developed in-house ELISA. In all the strains, extracellular levels of toxin A increased over $24 \mathrm{~h}$. Ribotype 027 produced significantly greater amounts of toxin A from $8 \mathrm{~h}$. By the stationary phase, ribotype 027 and VPI 10463 produced markedly more toxin than ribotypes 106 and 001 . Strain 630 produced the least toxin A. Error bars, SEM of six experiments. Lower $y$ axis, $0-100 \mathrm{ng} \mathrm{ml}^{-1}$; upper $y$ axis, 100-2000 $\mathrm{ng} \mathrm{ml}^{-1}$. (c) Toxin $\mathrm{B}$ was quantified by a modified cytotoxicity assay. Ribotype 027 produced significantly greater amounts of toxin B from $8 \mathrm{~h}$, while that in VPI 10463 increased steadily over time. In ribotypes 106 and 001 , the amounts of toxin
$\mathrm{B}$ increased gradually till $20 \mathrm{~h}$ and then showed a sudden increase at $24 \mathrm{~h}$. In strain 630, toxin B levels decreased over time. Error bars, SEM of six experiments. Lower $y$ axis, 0-250 $\mathrm{ng} \mathrm{ml}^{-1}$; upper $y$ axis, 250-2000 $\mathrm{ng} \mathrm{m}^{-1}$.

significantly higher than that of strain $630(P<0.001)$. Thus, varying growth rates do not appear to explain the degrees of virulence observed in different strains of $C$. difficile.

\section{C. difficile ribotype 027 produces significantly more toxin than other strains}

Total toxin $(\mathrm{A}+\mathrm{B})$ production as measured by the combined ELISA kit varied significantly between the strains studied (Fig. 2a). In ribotype 027, total toxin production increased significantly between 8 and $12 \mathrm{~h}$. By $12 \mathrm{~h}$, ribotype 027 and VPI 10463 produced significantly more toxin than the other strains $(P<0.001)$, which showed a gradual increase in toxin production over time. Ribotype 106 produced more toxin than 001, which in turn was greater than strain 630 . Over the $24 \mathrm{~h}$, ribotype 027 and VPI 10463 produced significantly higher amounts of total toxin $(P<0.001)$. Beyond $12 \mathrm{~h}$, the levels of toxin production in ribotype 027 and VPI 10463 could not be determined due to saturation of the assay. Thus, to investigate further the amounts of individual toxins produced by the different strains, quantitative methods were developed to detect each of the toxins.

Toxin A was detected in the cultures of all strains by ELISA (Fig. 2b). Ribotype 027 produced the most toxin A up to $12 \mathrm{~h}(P<0.001)$ and the amounts increased till $24 \mathrm{~h}$. All the other strains produced low levels of toxin A till $12 \mathrm{~h}$. Beyond $12 \mathrm{~h}$, large amounts of toxin A were detected in cultures of VPI 10463, as expected, and the amounts were similar to those of ribotype 027. Ribotypes 106 and 001 produced toxin A at similar levels, which were significantly lower than those of VPI 10463 and ribotype $027(P<0.001)$ and slightly higher than those of strain 630. Toxin B production was assessed using a modified cytotoxicity assay, and levels were marginally higher than those of toxin A in all strains over time (Fig. 2c). VPI 10463 showed a steady increase in toxin $\mathrm{B}$ production that reached high levels at $24 \mathrm{~h}$. Ribotype 027 produced significantly more toxin $\mathrm{B}$ than the other strains at $8 \mathrm{~h}(P<0.01)$ and this level remained almost constant till $24 \mathrm{~h}$. In ribotypes 106 and 001 , toxin $\mathrm{B}$ production increased gradually up to $20 \mathrm{~h}$ and then increased sharply at $24 \mathrm{~h}$, possibly due to accumulation in the culture medium. Interestingly, in strain 630, toxin B production decreased over time. Overall, toxin B production in the hypervirulent ribotype 027 was significantly higher than that in the other test strains $(P<0.01)$.

From these results, it is evident that ribotype 027 produces significantly more toxin than the other strains. As 
observed by others, our data also suggested that ribotype 027 is capable of producing up to 20 times more toxin (A or B) than other strains (Warny et al., 2005), except VPI 10463. This was also true for seven isolates of ribotype 027 from Scotland and five from the Netherlands (data not shown) (Vohra \& Poxton, 2010). This appears to be a phenotypic advantage for this strain, enabling it to cause severe disease.

Another observation was the detection of moderately more toxin A than toxin $\mathrm{B}$ at $24 \mathrm{~h}$ in ribotypes 027 and 106 (Fig. 4). Toxin A, an enterotoxin with the ability to bind to epithelial cells in the gut via receptors (Krivan et al., 1986; Tucker \& Wilkins, 1991), causes initial damage by glucosylation of Rho proteins (Aktories et al., 2000). In animal studies, it has been observed that in the absence of toxin $\mathrm{A}$, toxin $\mathrm{B}$ is unable to induce the pathology characteristic of CDI (Lyerly et al., 1985). Even in cell cultures with $\mathrm{Caco} 2$ cells, it has been demonstrated that when toxin A challenge is removed, no damage is caused to the epithelial barrier (Sutton et al., 2008). Thus, large amounts of toxin A may contribute to increased disease severity and perhaps the increased potential of ribotypes 027, 106 and 001 to induce CDI in healthy humans: the greater the initial damage to the gut by toxin $\mathrm{A}$, the greater the chance of toxin $\mathrm{B}$ causing extensive cytotoxicity. However, outbreaks caused by $\mathrm{A}^{-} \mathrm{B}^{+}$strains have been reported (Drudy et al., 2007), questioning the clinical importance of toxin $\mathrm{A}$ in disease. Toxin $\mathrm{B}$ is 1000-fold more cytotoxic than toxin A; however, its role in the development of the characteristic pathology of CDI is debated, though $\mathrm{A}^{+} \mathrm{B}^{-}$strains have not yet been isolated. It has also been shown that toxin B knockout strains are ineffective at causing fatal disease in hamsters (Lyras et al., 2009). However, more recently it has been suggested that both toxins are important in CDI (Kuehne et al., 2010). Whatever the importance of toxin B in disease, it is clear that the current epidemic strains produce large quantities of it. This, coupled with the production of large amounts of toxin A, could explain the severity of disease associated with ribotypes 027,106 and 001 .

\section{High toxin producers show increased transcription of the PaLoc genes}

Transcriptional analysis of the PaLoc genes was performed by real-time RT-PCR (Fig. 3). In VPI 10463, the transcription of $t c d A, t c d B$ and $t c d R$ increased over $24 \mathrm{~h}$, while that of $t c d C$ decreased after $8 \mathrm{~h}$, as shown by Hundsberger et al. (1997). tcdE levels were found to increase till $12 \mathrm{~h}$, after which they decreased, with a transient increase at $24 \mathrm{~h}$. This served as a basis for transcription studies in the other strains using the methodology developed. However, varying patterns of PaLoc gene expression were observed in the other strains.

$t c d A$ expression increased till $12 \mathrm{~h}$ in ribotype 027 , ribotype 106 and strain 630, and then decreased, whilst remaining almost constant in ribotype 001 over time. A similar trend was observed for $t c d B$ in ribotype 106 and strain 630, though in the latter, the levels were below the $4 \mathrm{~h}$ value. In ribotype 001 , an increase in $t c d B$ transcription was observed at $20 \mathrm{~h}$. Interestingly, ribotype 027 was the only strain to show constantly increasing $t c d B$ expression over the $24 \mathrm{~h}$ period studied, though it was less than that of $t c d A$. The pattern of $t c d A$ expression suggests that transcription peaks at $12 \mathrm{~h}$ and the toxin levels detected in culture thereafter are the result of accumulation. This was observed less markedly and from $8 \mathrm{~h}$ for toxin $\mathrm{B}$. This observed correlation between gene expression and toxin detection (Fig. 4) was analysed by expressing the results as the ratio of toxin production to toxin gene transcription. Though the transcription of $t c d B$ was lower than that of $t c d A$ in all the strains, the levels of toxin $B$ detected were always higher than those of toxin A, suggesting more efficient production of $\mathrm{TcdB}$ or perhaps greater degradation of TcdA in culture.

$t c d R$ transcription increased steadily over time in strain 630 , but in ribotypes 027,001 and 106, peak expression was observed at $12 \mathrm{~h}$, followed by a decline. A transient increase in expression was observed at $24 \mathrm{~h}$ in ribotypes 027 and 106. Notably, $t c d C$ transcription showed a similar pattern and at similar levels, contrary to the observations in VPI 10463.

$t c d C$ is the negative regulator of toxin production (Dupuy et al., 2008; Matamouros et al., 2007), and it has been shown that its transcription decreases as cultures enter stationary phase (Hundsberger et al., 1997). The levels of the protein itself have also been shown to diminish over time (Govind et al., 2006). Further, the deletions found in $t c d C$ in ribotype 027 have been used to explain the excessive toxin production in this strain, as the truncated TcdC protein would be ineffective in preventing the complexing of TcdR with RNA polymerase (Curry et al., 2007). Contrary to the gene and protein studies, our data showed that $t c d C$ transcription increased over time, at least till $12 \mathrm{~h}$, and then decreased. Though there was an evident decrease in $t c d C$ expression, it was not considered to fit into the pattern described elsewhere (Hundsberger et al., 1997), as the $t c d R$ expression observed showed a similar pattern and was at similar levels. This suggests that $t c d C$ might have a modulatory effect on toxin production, rather than a strictly inhibitory one. Also, both toxins, A and $\mathrm{B}$, were detected in the exponential and stationary phases of growth, despite increasing $t c d C$ expression. Others have also shown this expression of $t c d C$ in both the phases of growth, though slightly diminished in the stationary phase (Dineen et al., 2007; Karlsson et al., 2008). It is possible that TcdC, being a membraneassociated protein, has an effect on the release of toxins. These hypotheses could be tested by gene knockout and protein interaction studies, and would greatly add to the understanding of toxin production and release in $C$. difficile. 


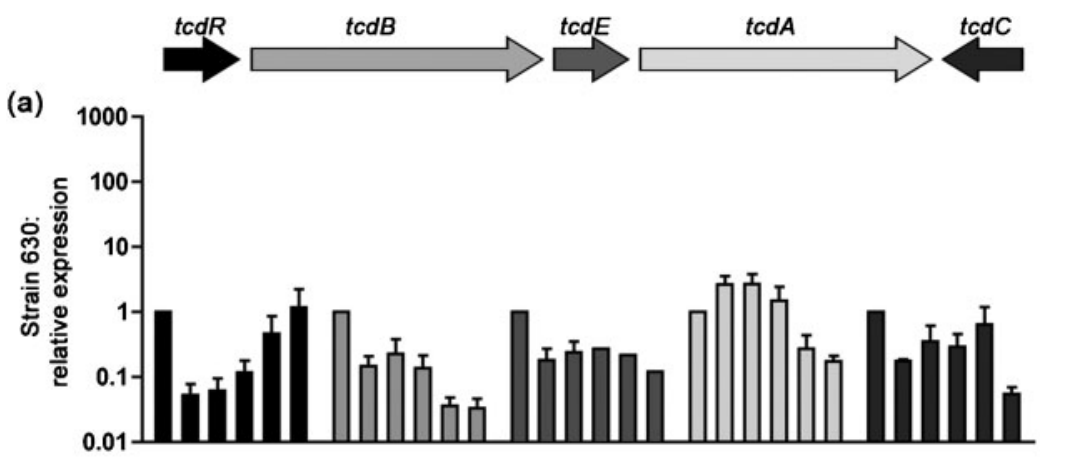

(b)

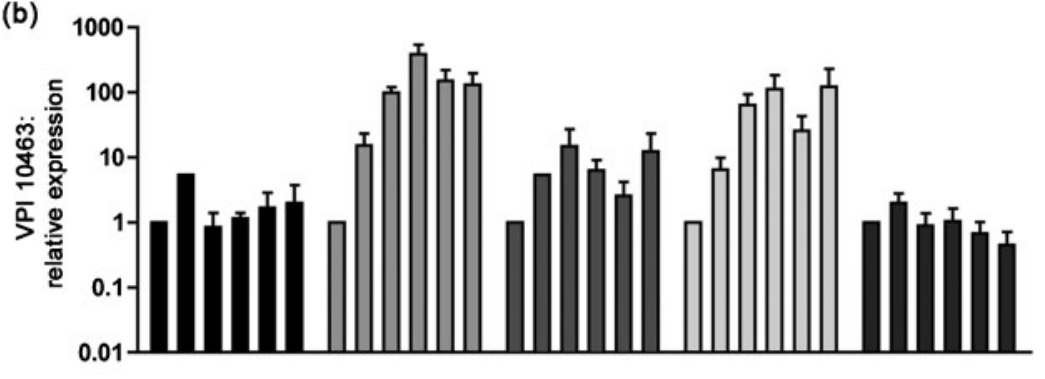

(c)

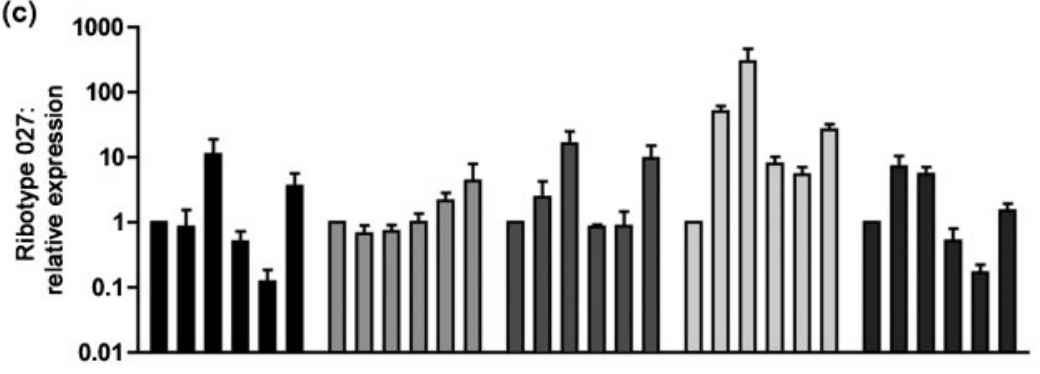

(d)
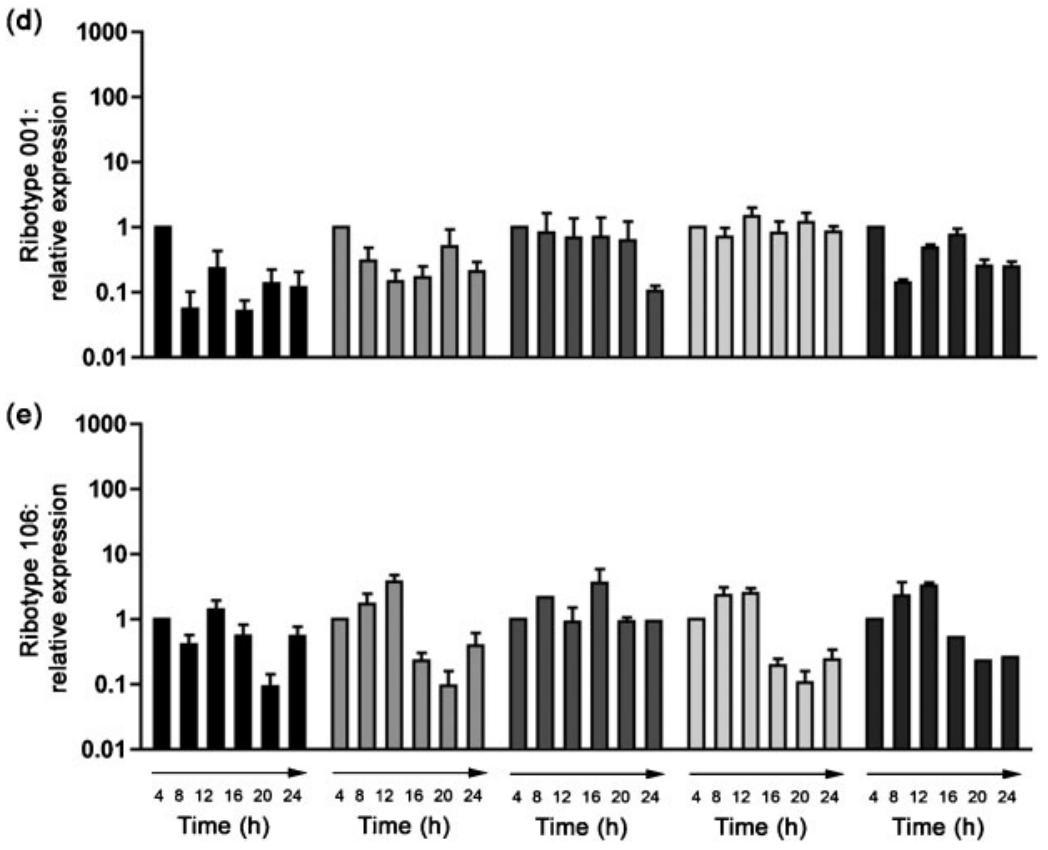

Fig. 3. Transcription of the PaLoc in five $C$. difficile strains. Transcription of the PaLoc genes was studied by real-time RT-PCR in (a) strain 630, (b) VPI 10463, (c) ribotype 027, (d) ribotype 001 and (e) ribotype 106. The expression of all the genes was normalized to that of $r r n$, using the $4 \mathrm{~h}$ value as the baseline of expression. (a) In strain $630, t c d A$ expression increased till $12 \mathrm{~h}$ and then decreased, similar to $t c d B$, though that of $t c d B$ was below the $4 \mathrm{~h}$ value. $t c d R$ and $t c d C$ expression increased over time, while that of $t c d E$ remained constant. (b) In VPI 10463, the expression of $t c d R, t c d A, t c d B$ and $t c d E$ increased over the $24 \mathrm{~h}$, while that of $t c d C$ decreased. (c) In ribotype 027, the transcription of $t c d R, t c d E, t c d A$ and $t c d C$ peaked at $12 \mathrm{~h}$ and then decreased. $t c d B$ transcription increased over $24 \mathrm{~h}$. (d) In ribotype 001, tcdR and $t c d C$ transcription was similar, while that of $t c d B$, tcdE and $t c d A$ did not vary considerably over time. (e) In ribotype 106, tcdR, $t c d B, t c d A$ and $t c d C$ transcription peaked at $12 \mathrm{~h}$, while that of $t c d E$ increased till $16 \mathrm{~h}$. Thereafter, expression of all the genes decreased. Error bars, SEM of six experiments for $t c d A$ and $t c d B$ expression, and four experiments for $t c d R, t c d E$ and $t c d C$ expression. 

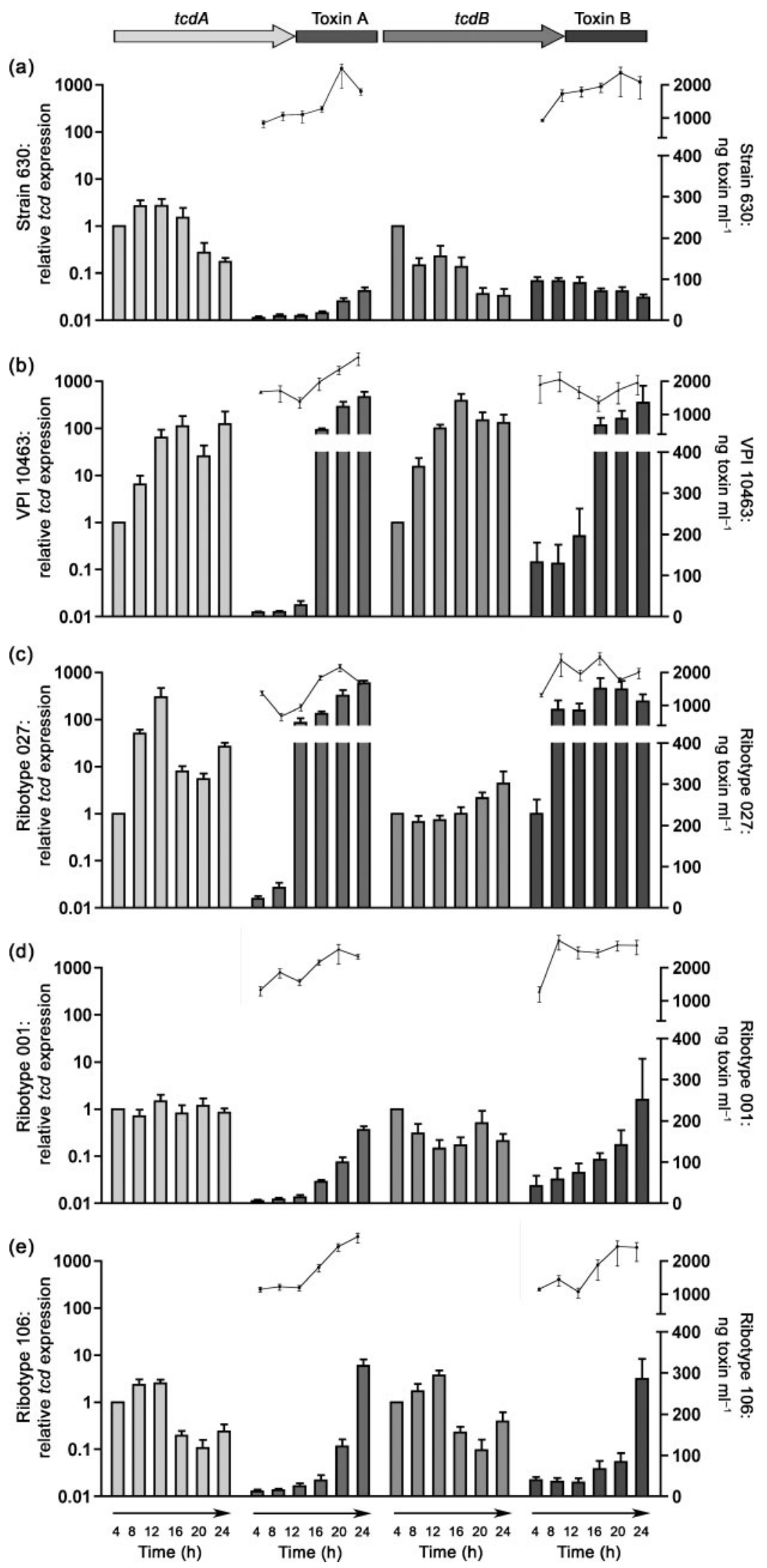

Fig. 4. $t c d A$ and $t c d B$ transcription and the corresponding toxin $\mathrm{A}$ and toxin $\mathrm{B}$ production. The transcription of the toxin genes $t c d A$ and $t c d B$ and the corresponding production of toxin $A$ and toxin $B$ was studied in (a) strain 630, (b) VPI 10463, (c) ribotype 027, (d) ribotype 001 and (e) ribotype 106. The extracellular levels of both toxins increased over time in all the strains, even when gene expression decreased. Ribotype 027 produced greater amounts of both toxins and also showed greater gene expression. The correlation of toxin production to toxin gene transcription was assessed by analysing ratios of toxin $A$ value: tcdA expression and toxin $B$ value: $t c d B$ expression at the different time points. This is represented by the line graphs above the toxin values for each toxin $\left(\log _{10}\right.$ scale ranging from $10^{-1}$ to $10^{5}$ ). In all the strains, the release of toxin $A$ at $12 \mathrm{~h}$ is evident. For toxin $B$, earlier release is indicated. Error bars, SEM of six experiments. 

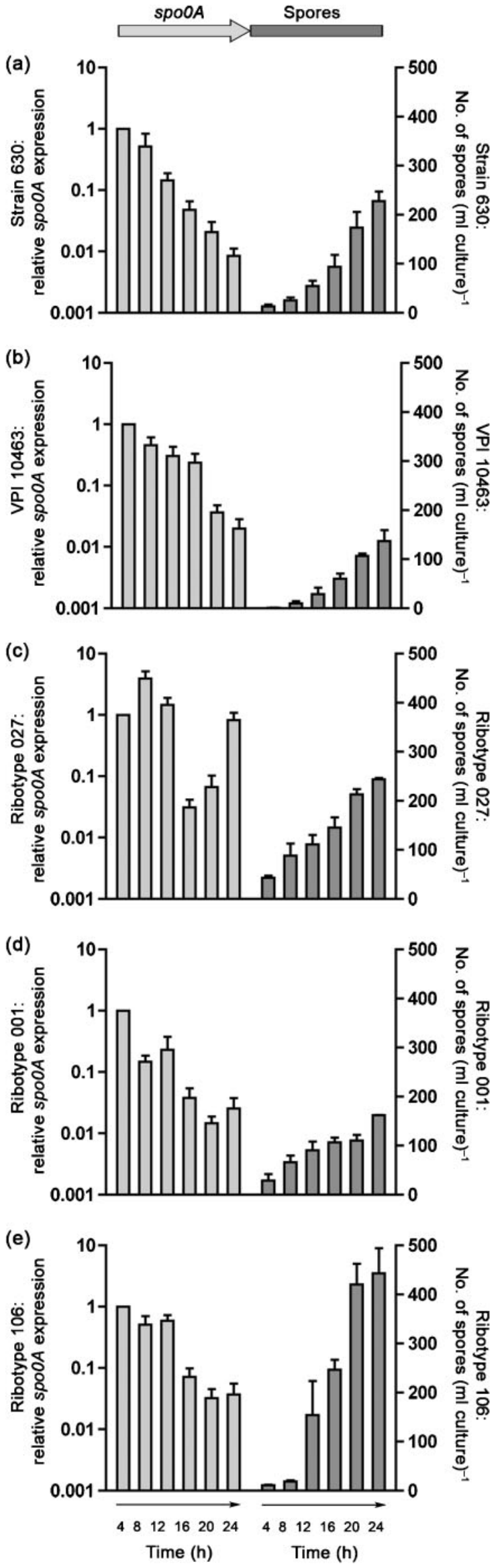

Fig. 5. $s p o O A$ transcription and spore production in five $C$. difficile strains. spoOA transcription, normalized to that of $r r n$, in (a) strain 630, (b) VPI 10463, (c) ribotype 027, (d) ribotype 001 and (e) ribotype 106 decreased over time, except for the slight increase in ribotype 027 at 8 and $12 \mathrm{~h}$. The number of spores detected in the cultures of all the strains increased over the $24 \mathrm{~h}$, with ribotype 106 producing the highest number of spores, followed by ribotypes 027 and 001 and strain 630. VPI 10463 produced the lowest number of spores. Error bars, SEM of six experiments for the transcription of $s p o O A$ and three experiments for spore production.

$t c d E$ transcription was also studied, though not in a very efficient reaction. However, the results obtained showed that there was a major increase, approximately 15 -fold, in $t c d E$ expression till $12 \mathrm{~h}$ in ribotype 027 and VPI 10463, the highest toxin producers, which corresponds to the time beyond which large amounts of toxin are detected in the cultures of these strains. The almost steady expression of $t c d E$ in the other strains corresponded to the slower release of toxins seen in those strains. Thus, it is likely that TcdE plays an important role in the release of the $C$. difficile toxins, given its holin-like properties (Tan et al., 2001). The increased $t c d E$ transcription in ribotype 027 may also contribute to hypervirulence.

\section{Currently common $C$. difficile ribotypes produce more spores than a previously dominant strain}

Sporulation is the other key trait of $C$. difficile that enables it to survive and spread in the environment. That sporulation and toxin production are alternate mechanisms for survival has been debated (Kamiya et al., 1992). VPI 10463 fits this idea, showing high toxin production and low sporulation. Contrary to this, ribotype 027 has been shown to produce high levels of both toxins and spores, and this has been observed in 12 different isolates of ribotype 027 (data not shown) (Vohra \& Poxton, 2010).

All the strains studied here produced alcohol-resistant spores, and their numbers in culture increased over time (Fig. 5). Ribotype 106 produced significantly more spores $(P<0.001)$ than the other strains, though this significance was less when compared with spore production by ribotype $027(P<0.05)$. At $24 \mathrm{~h}$, a final count of 443 spores ( $\mathrm{ml}$ culture $)^{-1}$ was obtained for ribotype 106, which was significantly higher than that of the other strains. VPI 10463 produced the fewest spores. The number of spores obtained was very low, although this was possibly due to the absence of bile salts, which enhance spore germination (Wilson, 1983), in the medium used.

spo0A, the master regulator of sporulation, was selected as the indicator of the magnitude of the spore-producing capacity of the $C$. difficile strains studied. spo0A 
transcription in all the strains decreased over time (Fig. 5). In the epidemic strains, however, there was a slight difference in the pattern of expression: in ribotype 027, spo0A expression increased at $8 \mathrm{~h}$ before decreasing and then spiked at $24 \mathrm{~h}$, whilst in ribotypes 106 and 001 , the levels of expression increased marginally at $12 \mathrm{~h}$ before falling. These differences, however, were not significant.

Despite the expected decrease in gene expression, the trends over the first few hours suggested subtle interstrain differences. Perhaps the increased duration of transcription of $s p o 0 A$ in the early stages of growth enhances the expression of the subsequent genes involved in the process, resulting in a greater number of spores being produced and released into the environment, irrespective of environmental stresses. The link between toxin and spore production has recently been described: spo0A mutants show decreased sporulation and toxin production (Underwood et al., 2009). Thus, the observed increase in spo0A transcription in ribotype $027 \mathrm{might}$ also increase its toxin production and add to its hypervirulence.

During the preparation of this manuscript, a similar study was published comparing hypervirulent ribotype 027 (BI) strains with non-hypervirulent strains (Merrigan et al., 2010). The increase in the transcription of the PaLoc genes, including $t c d C$, was also observed in that study, and those authors too hypothesize a modulatory function for TcdC. However, unlike their results, we detected toxin production in all our strains in the exponential phase of growth as well as the stationary phase. It is possible that this difference was due to the medium used. We used anaerobic incubation medium (AIM) in our experiments, a medium that does not contain any glucose, which inhibits toxin production (Dupuy \& Sonenshein, 1998; Karlsson et al., 1999). It does contain cysteine, though at subinhibitory levels. This might explain the earlier detection of toxins in our study and the greater levels detected in the stationary phase of growth. This might also address the significantly higher $t c d A$ transcription in ribotype 027 observed in our study.

Although a single isolate was tested for each ribotype, from the data presented here, we can conclude that ribotype 027 has the ability to produce large amounts of toxins and spores, both key phenotypic advantages that are likely to have aided its emergence. Further, ribotype 106 possesses traits that may directly address its presence as the strain most commonly associated with CDI in Scotland. The increased toxin and spore production in the current epidemic strains corresponds directly with the severity of disease and extent of spread associated with them, and gives further insight into the evolving bacterial factors that affect the epidemiology of CDI.

\section{ACKNOWLEDGEMENTS}

This work is part of a $\mathrm{PhD}$ funded by the Overseas Research Students Awards Scheme and a University of Edinburgh Centre for Infectious Diseases PhD Studentship. We would like to thank Professor D. Gally, and Drs N. H. Anderson and A. J. Wroe, for their guidance and helpful discussion. This work was presented in part as a poster at the 20th European Congress of Clinical Microbiology and Infectious Diseases (ECCMID), Vienna, Austria, April 2010.

\section{REFERENCES}

Akerlund, T., Svenungsson, B., Lagergren, A. \& Burman, L. G. (2006). Correlation of disease severity with fecal toxin levels in patients with Clostridium difficile-associated diarrhea and distribution of PCR ribotypes and toxin yields in vitro of corresponding isolates. J Clin Microbiol 44, 353-358.

Akerlund, T., Persson, I., Unemo, M., Norén, T., Svenungsson, B., Wullt, M. \& Burman, L. G. (2008). Increased sporulation rate of epidemic Clostridium difficile type 027/NAP1. J Clin Microbiol 46, 1530-1533.

Aktories, K., Schmidt, G. \& Just, I. (2000). Rho GTPases as targets of bacterial protein toxins. Biol Chem 381, 421-426.

Arvand, M., Hauri, A. M., Zaiss, N. H., Witte, W. \& Bettge-Weller, G. (2009). Clostridium difficile ribotypes 001, 017, and 027 are associated with lethal C. difficile infection in Hesse, Germany. Euro Surveill 14, $1-4$.

Bartlett, J. G., Moon, N., Chang, T. W., Taylor, N. \& Onderdonk, A. B. (1978). Role of Clostridium difficile in antibiotic-associated pseudomembranous colitis. Gastroenterology 75, 778-782.

Brown, R., Collee, J. \& Poxton, I. (1996). Bacteroides, Fusobacterium and other Gram-negative anaerobic rods; anaerobic cocci; identification of anaerobes. In Mackie and McCartney Practical Medical Microbiology. Edited by J. Collee, A. Fraser, B. Marmion \& A. Simmons. London: Churchill Livingstone.

Curry, S. R., Marsh, J. W., Muto, C. A., O'Leary, M. M., Pasculle, A. W. \& Harrison, L. H. (2007). $t c d C$ genotypes associated with severe TcdC truncation in an epidemic clone and other strains of Clostridium difficile. J Clin Microbiol 45, 215-221.

Dineen, S. S., Villapakkam, A. C., Nordman, J. T. \& Sonenshein, A. L. (2007). Repression of Clostridium difficile toxin gene expression by CodY. Mol Microbiol 66, 206-219.

Drudy, D., Harnedy, N., Fanning, S., Hannan, M. \& Kyne, L. (2007). Emergence and control of fluoroquinolone-resistant, toxin Anegative, toxin B-positive Clostridium difficile. Infect Control Hosp Epidemiol 28, 932-940.

Dupuy, B. \& Sonenshein, A. L. (1998). Regulated transcription of Clostridium difficile toxin genes. Mol Microbiol 27, 107-120.

Dupuy, B., Govind, R., Antunes, A. \& Matamouros, S. (2008). Clostridium difficile toxin synthesis is negatively regulated by TcdC. J Med Microbiol 57, 685-689.

Freeman, J., Baines, S. D., Saxton, K. \& Wilcox, M. H. (2007). Effect of metronidazole on growth and toxin production by epidemic Clostridium difficile PCR ribotypes 001 and 027 in a human gut model. J Antimicrob Chemother 60, 83-91.

George, R. H., Symonds, J. M., Dimock, F., Brown, J. D., Arabi, Y., Shinagawa, N., Keighley, M. R., Alexander-Williams, J. \& Burdon, D. W. (1978). Identification of Clostridium difficile as a cause of pseudomembranous colitis. BMJ 1, 695. 
Govind, R., Vediyappan, G., Rolfe, R. D. \& Fralick, J. A. (2006). Evidence that Clostridium difficile TcdC is a membrane-associated protein. J Bacteriol 188, 3716-3720.

Health Protection Scotland (2008). Annual report on the surveillance of Clostridium difficile associated disease (CDAD) in Scotland, October 2006-September 2007. HPS Weekly Report 42, 3-9. http:// www.documents.hps.scot.nhs.uk/hai/sshaip/publications/cdad/200712-20-ar-cdad.pdf

Health Protection Scotland (2010). Quarterly report on the surveillance of Clostridium difficile infection (CDI) in Scotland, January 2010-March 2010. HPS Weekly Report 27, 261-269. http:// www.documents.hps.scot.nhs.uk/ewr/pdf2010/1027.pdf

Hundsberger, T., Braun, V., Weidmann, M., Leukel, P., Sauerborn, M. \& von Eichel-Streiber, C. (1997). Transcription analysis of the genes $t c d A-E$ of the pathogenicity locus of Clostridium difficile. Eur J Biochem 244, 735-742.

Jump, R. L. P., Pultz, M. J. \& Donskey, C. J. (2007). Vegetative Clostridium difficile survives in room air, on moist surfaces and in gastric contents with reduced acidity: a potential mechanism to explain the association between proton pump inhibitors and $C$. difficile-associated diarrhea? Antimicrob Agents Chemother 51, 2883 2887.

Kamiya, S., Ogura, H., Meng, X. Q. \& Nakamura, S. (1992). Correlation between cytotoxin production and sporulation in Clostridium difficile. J Med Microbiol 37, 206-210.

Karlsson, S., Burman, L. G. \& Akerlund, T. (1999). Suppression of toxin production in Clostridium difficile VPI 10463 by amino acids. Microbiology 145, 1683-1693.

Karlsson, S., Burman, L. G. \& Akerlund, T. (2008). Induction of toxins in Clostridium difficile is associated with dramatic changes of its metabolism. Microbiology 154, 3430-3436.

Krivan, H. C., Clark, G. F., Smith, D. F. \& Wilkins, T. D. (1986). Cell surface binding site for Clostridium difficile enterotoxin: evidence for a glycoconjugate containing the sequence Gal alpha 1-3Gal beta 14GlcNAc. Infect Immun 53, 573-581.

Kuehne, S. A., Cartman, S. T., Heap, J. T., Kelly, M. L., Cockayne, A. \& Minton, N. P. (2010). The role of toxin A and toxin B in Clostridium difficile infection. Nature 467, 711-713.

Kuijper, E. J., Coignard, B., Brazier, J. S., Suetens, C., Drudy, D., Wiuff, C., Pituch, H., Reichert, P., Schneider, F. \& other authors (2007). Update of Clostridium difficile-associated disease due to PCR ribotype 027 in Europe. Euro Surveill 12, E1-E2.

Larson, H. E., Price, A. B., Honour, P. \& Borriello, S. P. (1978). Clostridium difficile and the aetiology of pseudomembranous colitis. Lancet 311, 1063-1066.

Loo, V. G., Poirier, L., Miller, M. A., Oughton, M., Libman, M. D., Michaud, S., Bourgault, A. M., Nguyen, T., Frenette, C. \& other authors (2005). A predominantly clonal multi-institutional outbreak of Clostridium difficile-associated diarrhea with high morbidity and mortality. N Engl J Med 353, 2442-2449.

Lyerly, D. M., Saum, K. E., MacDonald, D. K. \& Wilkins, T. D. (1985). Effects of Clostridium difficile toxins given intragastrically to animals. Infect Immun 47, 349-352.

Lyras, D., O'Connor, J. R., Howarth, P. M., Sambol, S. P., Carter, G. P., Phumoonna, T., Poon, R., Adams, V., Vedantam, G. \& other authors (2009). Toxin B is essential for virulence of Clostridium difficile. Nature 458, 1176-1179.

MacCannell, D. R., Louie, T. J., Gregson, D. B., Laverdiere, M., Labbe, A.-C., Laing, F. \& Henwick, S. (2006). Molecular analysis of Clostridium difficile PCR ribotype 027 isolates from Eastern and Western Canada. J Clin Microbiol 44, 2147-2152.
Matamouros, S., England, P. \& Dupuy, B. (2007). Clostridium difficile toxin expression is inhibited by the novel regulator TcdC. $\mathrm{Mol}$ Microbiol 64, 1274-1288.

McFarland, L. V., Beneda, H. W., Clarridge, J. E. \& Raugi, G. J. (2007). Implications of the changing face of Clostridium difficile disease for health care practitioners. Am J Infect Control 35, 237253.

Merrigan, M., Venugopal, A., Mallozzi, M., Roxas, B., Viswanathan, V. K., Johnson, S., Gerding, D. N. \& Vedantam, G. (2010). Human hypervirulent Clostridium difficile strains exhibit increased sporulation as well as robust toxin production. J Bacteriol 192, 49044911.

Mutlu, E., Wroe, A. J., Sanchez-Hurtado, K., Brazier, J. S. \& Poxton, I. R. (2007). Molecular characterization and antimicrobial susceptibility patterns of Clostridium difficile strains isolated from hospitals in south-east Scotland. J Med Microbiol 56, 921929.

Pépin, J., Valiquette, L., Alary, M.-E., Villemure, P., Pelletier, A., Forget, K., Pépin, K. \& Chouinard, D. (2004). Clostridium difficileassociated diarrhea in a region of Quebec from 1991 to 2003: a changing pattern of disease severity. CMAJ 171, 466-472.

Pépin, J., Valiquette, L. \& Cossette, B. (2005). Mortality attributable to nosocomial Clostridium difficile-associated disease during an epidemic caused by a hypervirulent strain in Quebec. CMAJ 173, 1037-1042.

Pfaffl, M. W. (2001). A new mathematical model for relative quantification in real-time RT-PCR. Nucleic Acids Res 29, e45.

Riggs, M. M., Sethi, A. K., Zabarsky, T. F., Eckstein, E. C., Jump, R. L. P. \& Donskey, C. J. (2007). Asymptomatic carriers are a potential source for transmission of epidemic and nonepidemic Clostridium difficile strains among long-term care facility residents. Clin Infect Dis 45, 992-998.

Rozen, S. \& Skaletsky, H. (2000). Primer3 on the WWW for general users and for biologist programmers. Methods Mol Biol 132, 365386.

Smith, A. (2005). Outbreak of Clostridium difficile infection in an English hospital linked to hypertoxin-producing strains in Canada and the US. Euro Surveill 10, E050630, 2. http://www.eurosurveillance. org/images/dynamic/EQ/v05n03/v05n03.pdf

Spigaglia, P. \& Mastrantonio, P. (2002). Molecular analysis of the pathogenicity locus and polymorphism in the putative negative regulator of toxin production $(\mathrm{TcdC})$ among Clostridium difficile clinical isolates. J Clin Microbiol 40, 3470-3475.

Sundram, F., Guyot, A., Carboo, I., Green, S., Lilaonitkul, M. \& Scourfield, A. (2009). Clostridium difficile ribotypes 027 and 106: clinical outcomes and risk factors. J Hosp Infect 72, 111-118.

Sutton, P. A., Li, S., Webb, J., Solomon, K., Brazier, J. \& Mahida, Y. R. (2008). Essential role of toxin A in C. difficile 027 and reference strain supernatant-mediated disruption of Caco-2 intestinal epithelial barrier function. Clin Exp Immunol 153, 439-447.

Tan, K. S., Wee, B. Y. \& Song, K. P. (2001). Evidence for holin function of $t c d E$ gene in the pathogenicity of Clostridium difficile. J Med Microbiol 50, 613-619.

Taori, S. K., Hall, V. \& Poxton, I. (2009). Changes in antibiotic susceptibility and ribotypes in Clostridium difficile isolates from southern Scotland, 1979-2004. J Med Microbiol 59, 338-344.

Tucker, K. D. \& Wilkins, T. D. (1991). Toxin A of Clostridium difficile binds to the human carbohydrate antigens I, X, and Y. Infect Immun 59, 73-78.

Underwood, S., Guan, S., Vijayasubhash, V., Baines, S. D., Graham, L., Lewis, R. J., Wilcox, M. H. \& Stephenson, K. (2009). Characterization of 
the sporulation initiation pathway of Clostridium difficile and its role in toxin production. J Bacteriol 191, 7296-7305.

Vohra, P. \& Poxton, I. R. (2010). Characterisation of Clostridium difficile ribotype 027 strains in Scotland. Poster no. SP-4, presented at: Anaerobe 2010, The 10th Biennial Congress of the Anaerobe Society of the Americas, July 7-9, Philadelphia, PA, USA.

Warny, M., Pepin, J., Fang, A., Killgore, G., Thompson, A., Brazier, J., Frost, E. \& McDonald, L. C. (2005). Toxin production by an emerging strain of Clostridium difficile associated with outbreaks of severe disease in North America and Europe. Lancet 366, 10791084.

Wilson, K. H. (1983). Efficiency of various bile salt preparations for stimulation of Clostridium difficile spore germination. J Clin Microbiol 18, 1017-1019.

Wüst, J., Sullivan, N. M., Hardegger, U. \& Wilkins, T. D. (1982). Investigation of an outbreak of antibiotic-associated colitis by various typing methods. J Clin Microbiol 16, 1096-1101.

Edited by: T. J. Mitchell 